\title{
Fish oil combined with SCFA synergistically prevent tissue accumulation of NEFA during weight loss in obese mice
}

\author{
Maiken H. Pedersen ${ }^{1,2}$, Lotte Lauritzen ${ }^{2}$ and Lars I. Hellgren ${ }^{1 *}$ \\ ${ }^{1}$ Department of Systems Biology, Center for Biological Sequence Analysis, Technical University of Denmark, 2800 Lyngby, \\ Denmark \\ ${ }^{2}$ Department of Human Nutrition, University of Copenhagen, 1958 Frederiksberg C, Denmark
}

(Received 13 July 2010 - Revised 15 December 2010 - Accepted 16 February 2011 - First published online 3 June 2011)

\section{Abstract}

Based on their proposed metabolic effects, we examined whether fish oil (FO) and SCFA, alone or in combination, accelerate weight loss and the resultant metabolic improvements. Obesity was induced in male C57BL/6J mice by high-energy feeding for 10 weeks. The mice were transferred to a low-fat diet $(2 \cdot 5 \mathrm{w} \%)$ for 4 weeks, the source of fat being either FO, a lard-safflower oil mix (control), or both types combined with SCFA. Weight, fasting insulin, tissue and serum lipid concentrations, as well as mRNA amount of genes related to adipose inflammation and hepatic fat oxidation were determined. All groups lost weight and showed reduced fasting insulin concentrations and reduced liver TAG. However, weight loss on the control-fat diet caused significant increase in hepatic and cardiac NEFA. Substituting $20 \%$ of the fat with SCFA increased weight loss by $48 \%$ and reduced fasting insulin 1.5 -fold more than the no-SCFA diets. It furthermore significantly increased the amount of mRNA for PPAR- $\alpha$, and decreased the mRNA amount for NF-кB in the liver and white adipose tissue. The FO diets enhanced improvement of tissue lipid levels. Thus, FO improved liver TAG and NEFA levels compared with weight loss on the control diet. Combining FO and SCFA further reduced tissue NEFA accumulation. In conclusion, we found that dietary SCFA had a significant impact on gene expression in the liver and adipose tissue, and that the effect of FO on tissue NEFA content was modified by SCFA. Thus, interactions between fatty acids should be considered when studying the effects of specific fatty acids.

Key words: Acetate: SCFA: Fish oil: Weight loss: Tissue NEFA

Dietary fatty acid chain length and degree of unsaturation are believed to influence the development of insulin resistance and n-3 long-chain (LC)-PUFA are particularly interesting due to their proposed anti-inflammatory and lipid-modulating effects. Weight loss is also expected to improve insulin sensitivity, restore normal function of the adipose tissue and reduce the level of inflammatory mediators. We therefore hypothesised that the addition of fish oil (FO) to a weight loss diet could improve the recovery of healthy metabolic function due to combined beneficial effects, including a potential increase in the rate of weight loss as indicated from studies with human test subjects ${ }^{(1-3)}$.

Several recent studies indicate that pro-inflammatory mediators produced in the adipose tissue promote the development of insulin resistance ${ }^{(4)}$. Fat-laden adipocytes excrete mediators that attract and activate macrophages ${ }^{(5-7)}$, which, in turn, excrete a number of inflammatory molecules including TNF- $\alpha^{(8)}$. TNF- $\alpha$ has been implicated to directly attenuate the insulin response in skeletal muscle cells, adipocytes and hepatocytes $^{(9-11)}$ and several molecular mechanisms have been suggested to link TNF- $\alpha$ to insulin resistance; for example, a direct inhibition of insulin-receptor autophosphorylation ${ }^{(11)}$. Furthermore, it has been shown that TNF- $\alpha$ can increase lipolysis, causing an increased flow of NEFA from adipocytes to non-adipose tissues, which is also expected to reduce insulin sensitivity in both skeletal muscles and the liver ${ }^{(12)}$.

A beneficial effect of $\mathrm{FO}$ on adipose inflammation in $\mathrm{db} / \mathrm{db}$ mice on a high-fat diet has been shown by Todoric et al. ${ }^{(13)}$. Furthermore, Krebs et al. ${ }^{(14)}$ found additional improvements in metabolic risk factors in women who consumed FO while losing weight. A plausible mechanism behind this effect could be that $n-3$ LC-PUFA or their metabolites activate PPAR, which leads to the induction of anti-inflammatory pathways. PPAR- $\gamma$ activation has been shown to reduce the production of TNF- $\alpha^{(15)}$. PPAR- $\gamma$ and PPAR- $\alpha$ activation has also been shown to inhibit the activation of NF- $\mathrm{KB}$, which is a key pro-inflammatory regulator ${ }^{(16)}$. PPAR- $\alpha$ is also a key regulator of genes involved in lipid oxidation and its activation

Abbreviations: Ctrl, control; FO, fish oil; GPR, G-protein-coupled receptor; LC-PUFA, long-chain-PUFA; SREBP-1c, sterol regulatory element binding protein-1c.

*Corresponding author: Lars I. Hellgren, fax +45886307 , email lih@bio.dtu.dk 
by dietary $n$-3 LC-PUFA may thus reduce the lipid load in non-adipose tissue and thereby increase insulin sensitivity ${ }^{(17)}$.

The inclusion of low-energy fat in exchange for normal fat may be another way to enhance recovery during weight loss. Low-energy fat of the Salatrim type contains high amounts of SCFA (acetate and propionate), which reduces the energy content to about $21 \mathrm{~kJ} / \mathrm{g}$ compared with $38 \mathrm{~kJ} / \mathrm{g}$ in normal dietary fat ${ }^{(18)}$. Furthermore, SCFA have been shown to induce the expression of PPAR- $\alpha$ and reduce the expression of NF- $\kappa$ B in a cell model ${ }^{(19)}$, indicating that SCFA might have antiinflammatory activity. Interestingly, acetate, the main organic acid in Salatrim, was found to exert strong anti-inflammatory activity through the activation of the G-protein-coupled receptor 43 (GPR43; also called NEFA receptor-2) ${ }^{(20)}$. GPR43 has been identified as a specific receptor for SCFA, and is mainly expressed in white and brown adipose tissue, the large intestine, dendritic cells and granulocytes ${ }^{(20,21)}$. In the white adipose tissue, GPR43 activation has been implicated in the regulation of lipid and glucose homeostasis and is today exploited as a promising drug target for the treatment of insulin resistance and type 2 diabetes ${ }^{(22)}$. Furthermore, it was also recently shown that activation of GPR43 in immune cells is required for normal resolution of certain inflammatory responses ${ }^{(21)}$. Thus, combining Salatrim with FO may result in synergism from the concomitant increase in PPAR- $\alpha$ expression and increased availability of its $n$-3 LC-PUFA agonists, as well as the anti-inflammatory effects and metabolic improvements in adipose tissue induced by the activation of GPR43.

The primary hypothesis of the present study was that obese mice on a hypoenergetic diet enriched with FO show improved rate of weight loss and greater improvements in metabolic risk factors compared with mice on a similar diet low in $n$-3 LC-PUFA. We furthermore explore the hypothesis that SCFA from Salatrim and $n-3$ LC-PUFA from FO have synergistic beneficial effects on metabolic function, enhancing the rate of which it returns to a lean phenotype during weight loss. Metabolic function was assessed by weight, fasting insulin, tissue lipid content and transcription of genes related to inflammation and lipid turnover.

\section{Methods}

\section{Animals and diets}

A total of forty-eight male C57BL/6J mice weighing 22.3 (SD 1.1) g (Charles River Laboratories International, Wilmington, MA, USA) were randomised into six groups. A lean reference group (lean) was kept on standard diet 1324 from Altromin (Lage, Germany) for the entire feeding period. In the five remaining groups, obesity was induced by feeding a high-energy diet for 10 weeks (60 energy\% fat) (D12492; Research Diets, New Brunswick, NJ, USA) and by the addition of $15 \mathrm{w} \%$ sucrose to drinking-water. Following the weight gain period, one group of mice continued on the high-fat diet to serve as an obese reference group (obese), while four groups were switched to ad libitum low-energy diets for 4 weeks $(2.5 \mathrm{w} \%$ fat added to powdered C1056 diet from Altromin). There was no difference in the average weight of the five obese groups after the weight gain period; the average was $35 \mathrm{~g}$ compared with $26 \mathrm{~g}$ in the lean reference group. The weight loss diets differed in fatty acid composition (Table 1) by the addition of either cod liver oil (FO) or a control (Ctrl) mix of lard and safflower oil (Ctrl) alone or with the exchange of $25 \mathrm{w} \%$ of the fat for Salatrim (FO + Salatrim, Ctrl + Salatrim) (the Salatrim was a gift from DANISCO, Brabrand, Denmark). The macronutrient composition in the four weight loss diets was identical with $611 \mathrm{~g} / \mathrm{kg}$ carbohydrates, $25 \mathrm{~g} / \mathrm{kg}$ fat, $172 \mathrm{~g} / \mathrm{kg}$ protein, $142 \mathrm{~g} / \mathrm{kg}$ free amino acids and $41 \mathrm{~g} / \mathrm{kg}$ fibre. The amount of fat added to the weight loss diets corresponded to the upper levels of a realistic daily FO intake for humans. Thus, the $2.5 \mathrm{w} \%$ equals 6 energy $\%$, which corresponds to a daily intake of $15 \mathrm{~g}$ FO for a person consuming $10000 \mathrm{~kJ} / \mathrm{d}$. The mice were housed in groups of four in wire cages at $20-22^{\circ} \mathrm{C}$, humidity between 45 and $65 \%$, and a $12 \mathrm{~h}$ light cycle. All handling and use of animals in the present study were approved by The Danish Animal Experiments Inspectorate and were carried out according to the guidelines of 'The Council of Europe Convention for the Protection of Vertebrate Animals used for Experimental and other Scientific purposes'.

\section{Physiological and biochemical measurements}

Weight was recorded weekly and fasting insulin was measured after 10 and 14 weeks. All mice were killed after 14 weeks by anaesthetisation $(0 \cdot 11 \mathrm{ml} / 25 \mathrm{~g}$ body weight of Ketaminol mixed with Narcoxyl 1000:125; Intervet Danmark AS, Skovlunde, Denmark) followed by a cardiac puncture from where all the blood was drawn. The blood was left to clot at room temperature for $20 \mathrm{~min}$ and the serum was collected after centrifugation. The heart, liver and adipose tissue were removed immediately and quickly frozen in liquid $\mathrm{N}_{2}$ before transfer to $\mathrm{a}-80^{\circ} \mathrm{C}$ freezer. Small fractions of the liver and adipose tissue were treated with RNAlater (Invitrogen, Taastrup,

Table 1. Fatty acid composition of the four weight loss diets that were fed to obese mice for 4 weeks*

\begin{tabular}{lccrr}
\hline Fatty acid $(\mathrm{g} / 100 \mathrm{~g})$ & Ctrl & Ctrl $+\mathrm{S}$ & FO & FO $+\mathrm{S}$ \\
\hline $2: 0$ & - & $6 \cdot 9$ & - & $6 \cdot 9$ \\
$3: 0$ & - & $0 \cdot 6$ & - & $0 \cdot 6$ \\
$14: 0$ & $2 \cdot 0$ & $1 \cdot 5$ & $4 \cdot 6$ & $3 \cdot 6$ \\
$16: 0$ & $25 \cdot 4$ & $22 \cdot 2$ & $11 \cdot 2$ & $10 \cdot 8$ \\
$16: 1 n-7$ & $2 \cdot 1$ & $1 \cdot 5$ & $6 \cdot 7$ & $5 \cdot 1$ \\
$18: 0$ & $12 \cdot 9$ & $25 \cdot 1$ & $2 \cdot 4$ & $14 \cdot 6$ \\
$18: 1 n-9$ & $34 \cdot 7$ & $25 \cdot 7$ & $23 \cdot 0$ & $17 \cdot 7$ \\
$18: 1 n-7$ & $2 \cdot 4$ & $1 \cdot 7$ & $3 \cdot 9$ & $3 \cdot 0$ \\
$18: 2 n-6$ & $17 \cdot 3$ & $12 \cdot 3$ & $4 \cdot 2$ & $3 \cdot 3$ \\
$18: 3 n-3$ & $0 \cdot 8$ & 0.6 & $3 \cdot 1$ & $2 \cdot 5$ \\
$18: 4 n-3$ & - & - & $2 \cdot 3$ & $1 \cdot 8$ \\
$20: 1 n-9$ & $0 \cdot 6$ & 0.5 & $10 \cdot 1$ & $7 \cdot 6$ \\
$22: 1 n-11$ & - & - & $6 \cdot 8$ & $5 \cdot 2$ \\
$20: 5 n-3$ & - & - & $7 \cdot 3$ & $5 \cdot 7$ \\
$22: 5 n-3$ & $0 \cdot 1$ & $0 \cdot 1$ & 0.9 & $0 \cdot 7$ \\
$22: 6 n-3$ & $0 \cdot 1$ & $0 \cdot 1$ & 10.5 & $8 \cdot 3$ \\
\hline
\end{tabular}

Ctrl, control diet; FO, fish oil diet; FO + S, 25 w\% of the normal fat was exchanged for Salatrim.

* The amount of each fatty acid is given as $\mathrm{g} / 100 \mathrm{~g}$ of total fatty acids. The total fat content was $2.5 \mathrm{w} \%$. 
Denmark) according to the manufacturer's recommendations, prior to freezing and later RNA isolation. Serum concentrations of insulin were analysed using ELISA kits (Mercodia AB, Uppsala, Sweden). Serum concentrations of TAG and NEFA were measured using kits from Wako Chemicals (Neuss, Germany) and a Cobas Mira auto-analyzer (Roche, Basel, Switzerland). Lipids were extracted from the tissue, the serum and the feed using the Folch procedure with the addition of nonadecanoic acid, dinonadecanoylglycerophosphorylcholine and triheptadecanoyl as internal standards before extraction ${ }^{(23)}$. Tissue phospholipids, NEFA and TAG were separated using preparative TLC; methyl esters of the lipids were prepared from the TLC scrapings or directly from the lipid extract of the serum and diets and separated and quantified using GLC as described earlier ${ }^{(24)}$.

\section{RNA extraction and real-time quantitative $P C R$}

Total RNA was isolated from the hepatic and adipose tissue using TRIzol (Invitrogen) and mRNA was further isolated from the total RNA by the use of $\mu$ MACS mRNA isolation kit (Miltenyi Biotec, Bergisch Gladbach, Germany). Reagents for first strand synthesis, as well as primer sets for real-time quantitative PCR, were purchased from Superarray (Frederick, MD, USA) in the form of commercial kits including CYBR green master mix for real-time detection. Actb, Gapdh and HSP90AB1 were used as reference genes. A Biometra Tpersonal thermocycler (Biometra, Goettingen, Germany) was used for first strand production, and a Bio-Rad iCycler iQ5 was used for PCR amplification and detection (Bio-Rad, Copenhagen, Denmark). The thermocyclers were programmed according to the recommendations from Superarray. Melting curve analysis was performed to check that only one target was amplified.

\section{Statistics}

All data are presented as group mean and standard deviations. GraphPad Prism 5 (GraphPad Software, Inc., La Jolla, CA, USA) was used for statistical analysis, and significance was set at $\alpha 0.05$. A two-way ANOVA was performed in order to assess the effect of fat type and Salatrim in the four weight loss diets, comparing data from these four groups only. If the ANOVA result showed a significant interaction, two-sided $t$-tests were computed to assess the differences between the individual groups. Data from the obese and lean reference groups are included in all graphs and tables for comparison.

\section{Results}

\section{Weight loss and fasting insulin}

All weight loss groups continuously lost weight and the obese reference group continued to gain weight between weeks 10 and 14 (Fig. 1(A)). Fasting insulin was changed accordingly in all groups (Fig. 1(B)). Furthermore, there was a significant correlation between the change in weight and change in fasting insulin $\left(r^{2} 0 \cdot 73, P<0 \cdot 0001\right)$. Salatrim caused a significant
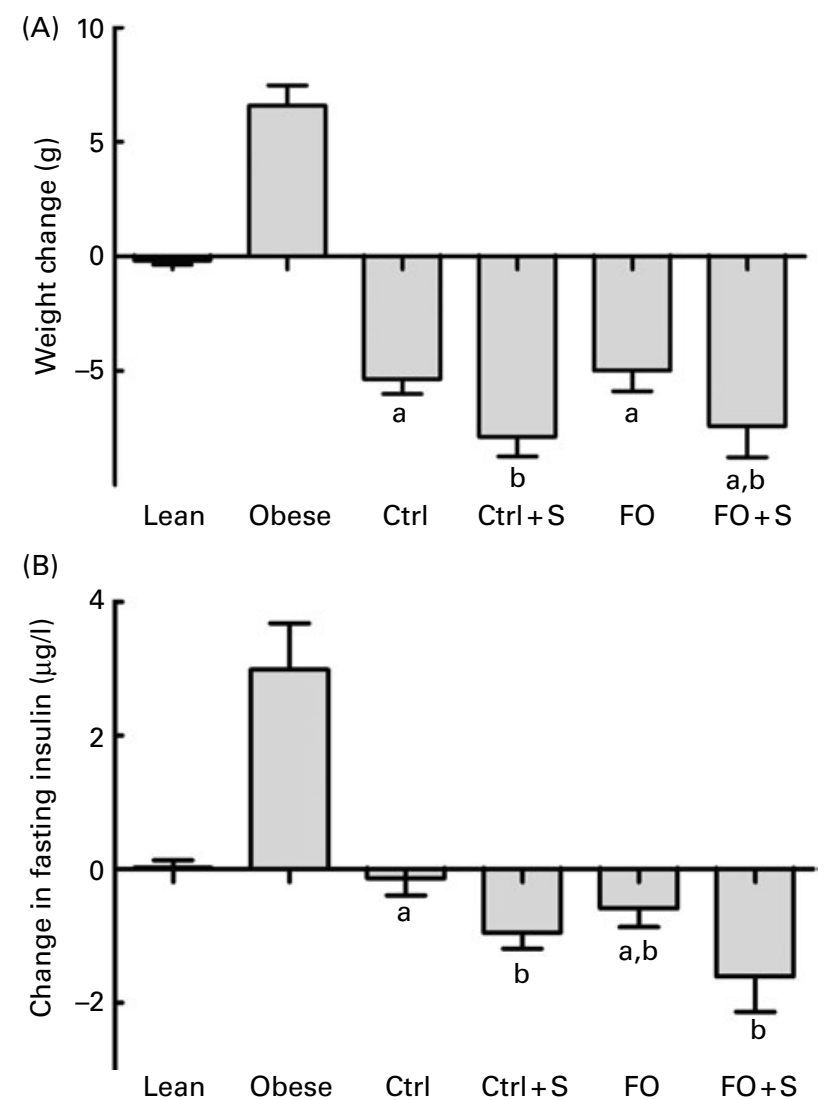

Fig. 1. The $(A)$ weight change and $(B)$ change in fasting insulin during the weight-loss phase (weeks 10-14) in the four weight loss groups and the lean and obese reference groups. Values are means and standard deviations, $n 8$. The lean and obese groups serve as reference groups for comparison and were not included in the statistical analyses. Statistical analysis was performed as a two-way ANOVA, using fish oil and Salatrim as variables. For both weight change and change in fasting insulin, two-way ANOVA showed an effect of Salatrim $(P<0.02)$. ${ }^{\mathrm{a}, \mathrm{b}}$ Mean values with unlike letters are significantly different $(P<0.05)$. Ctrl, control diet; FO, fish oil diet; FO $+\mathrm{S}, 25 \%$ of the normal fat was exchanged for Salatrim.

increase in weight loss, whereas the weight loss and subsequent change in fasting insulin in the FO and Ctrl groups did not differ (Fig. 1).

\section{Effects on lipid content and composition}

The analysis of EPA and DHA amounts in liver TAG showed that the FO groups responded to the treatment with about sixteen times more EPA and five times more DHA incorporation compared with the Ctrl groups (Fig. 2(A)). Analysis of the adipose tissue content of EPA and DHA showed that even though thef net flux of fatty acids during weight loss is assumed to be away from the adipose tissue, incorporation of the fatty acids from the FO diets had taken place (Fig. 2(B)). The hepatic phospholipid fatty acid composition and adipose tissue total fatty acid composition can be found in the online supplementary material (http://www.journals.cambridge.org/bjn). The concentration of TAG in the liver was reduced in both FO groups with no additional effect of Salatrim (Table 2). The serum concentration of NEFA was increased in the FO groups 

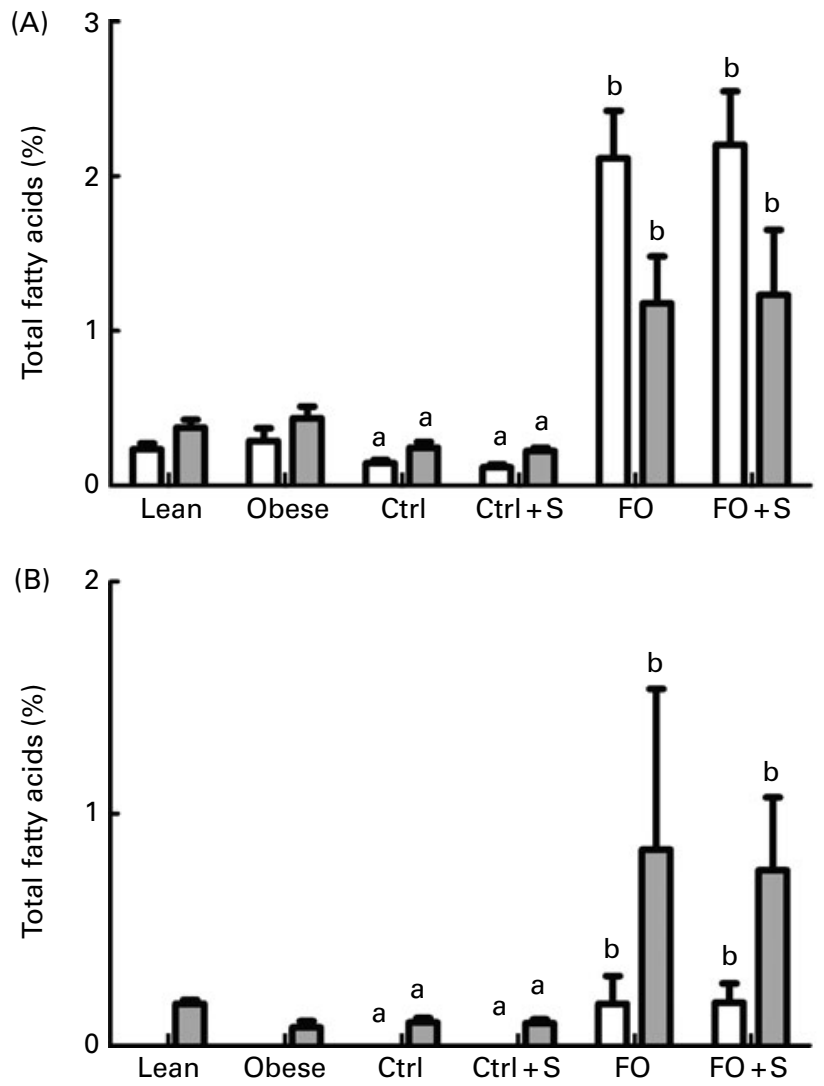

Fig. 2. The percentage of EPA $(\square)$ and DHA ( $\square$ ) in the (A) liver and (B) adipose tissue TAG as a percentage of total fatty acids in TAG. Otherwise as in Fig. 1. ${ }^{\mathrm{a}, \mathrm{b}}$ Mean values with unlike letters are significantly different. Ctrl, control diet; FO, fish oil diet; FO + S, $25 \%$ of the normal fat was exchanged for Salatrim.

but the serum concentration of TAG was not affected by any of the treatments (Table 2). It is noteworthy that, in both Ctrl groups weight loss induced a substantial increase in hepatic concentrations of NEFA compared with both the obese and the lean reference groups (Fig. 3(A) and (B)). FO reduced this weight loss-induced liver accumulation of NEFA, and there was a pronounced interaction between FO and Salatrim, which reduced NEFA even further (Fig. 3(A)). Analysis of cardiac NEFA accumulation also showed significant interaction between FO and Salatrim, which resulted in lower NEFA concentrations in the $\mathrm{FO}+\mathrm{S}$ group compared with the three other weight loss groups (Fig. 3(B)).

\section{Liver and adipose tissue mRNA amounts}

The addition of Salatrim to the diets resulted in significantly higher levels of PPAR- $\alpha$ mRNA and lower levels of mRNA for the P65 subunit of NF- $\mathrm{BB}$ in both the liver (Fig. 4 (A) and (B)) and adipose tissue (the supplementary material for this article can be found at http://www.journals.cambridge. org/bjn) compared with the effect of the weight loss diets without Salatrim. The Salatrim groups also had lower levels of sterol regulatory element binding protein-1c (SREBP-1c) mRNA in the liver (Fig. $4(\mathrm{C})$ ). TNF- $\alpha$ mRNA in the adipose tissue tended to be lower in the Salatrim groups compared with the pure FO and Ctrl groups (the supplementary material for this article can be found at http://www.journals. cambridge.org/bjn). Neither FO nor Salatrim significantly reduced the level of CD68 mRNA, which was used as a marker for macrophage infiltration in the adipose tissue (the supplementary material for this article can be found at http://www.journals.cambridge.org/bjn). No significant group differences were found in hepatic mRNA amounts of the SREBP-1c-regulated enzymes; fatty acid synthase and acetyl-CoA carboxylase, which together produce fatty acids from acetyl-CoA (the supplementary material for this article can be found at http://www.journals.cambridge.org/bjn). Nor were there any significant differences in the mRNA amount of stearoyl CoA desaturase-1 - a key lipogenic enzyme, or in the mRNA amounts of three PPAR- $\alpha$-regulated fatty acid oxidative enzymes; acyl-CoA synthetase (catalyses an initial step in long-chain fatty acid catabolism), the peroxisomal $\beta$-oxidation enzyme acyl-CoA oxidase, and the microsomal $\omega$-hydroxylase cytochrome P450 4A10 (the supplementary material for this article can be found at http:// www.journals.cambridge.org/bjn). The relative mRNA amounts of adipokines and genes associated with inflammation and energy metabolism can be found in the supplementary material at http://www.journals.cambridge.org/bjn. Salatrim treatment significantly reduced adipose mRNA levels of TGF- $\beta$, plasminogen activator inhibitor-1, leptin, resistin and the insulin receptor, and FO treatment also reduced adipose resistin mRNA.

Table 2. Concentrations of TAG and NEFA in the liver and serum after 4 weeks weight loss diet

(Mean values and standard deviations, $n 8$ )

\begin{tabular}{|c|c|c|c|c|c|c|c|c|c|c|c|c|c|c|c|}
\hline \multirow[b]{2}{*}{ Lipid* } & \multicolumn{2}{|c|}{ Lean† } & \multicolumn{2}{|c|}{ Obese† } & \multicolumn{2}{|c|}{ Ctrl } & \multicolumn{2}{|c|}{$\mathrm{Ctrl}+\mathrm{S}$} & \multicolumn{2}{|c|}{ FO } & \multicolumn{2}{|c|}{$\mathrm{FO}+\mathrm{S}$} & \multicolumn{3}{|c|}{$P \ddagger$} \\
\hline & Mean & SD & Mean & SD & Mean & SD & Mean & SD & Mean & SD & Mean & SD & FO & Salatrim & Interaction \\
\hline Hepatic TAG $(\mathrm{mg} / \mathrm{g})$ & 28 & 7 & 111 & 49 & 65 & 17 & 74 & 13 & 54 & 18 & 61 & 14 & 0.04 & & \\
\hline Hepatic NEFA (mg/g) & $1 \cdot 2$ & 0.3 & 1.2 & 0.2 & $2 \cdot 4$ & 0.4 & $3 \cdot 1$ & 0.5 & 1.9 & 0.3 & 1.5 & 0.2 & & & 0.0005 \\
\hline Cardiac TAG $(\mathrm{mg} / \mathrm{g})$ & 22 & 18 & 10 & 4.4 & 16 & $5 \cdot 3$ & 13 & 4.3 & 16 & $6 \cdot 1$ & 7 & 3.8 & & & \\
\hline Cardiac NEFA (mg/g) & 0.46 & $0 \cdot 18$ & 0.53 & 0.14 & 1.52 & 0.60 & $2 \cdot 19$ & 0.94 & 1.43 & 0.63 & 0.75 & 0.28 & & & 0.02 \\
\hline Serum TAG (mmol/l) & 0.50 & 0.14 & 0.51 & 0.12 & 0.86 & 0.34 & 0.58 & 0.19 & 0.85 & $0 \cdot 18$ & 0.92 & 0.24 & & & \\
\hline Serum NEFA (mmol/l) & 0.36 & $0 \cdot 10$ & 0.45 & 0.13 & 0.55 & 0.16 & 0.46 & 0.09 & 0.60 & 0.11 & 0.63 & 0.19 & 0.04 & & \\
\hline
\end{tabular}

Ctrl, control diet; FO, fish oil diet; FO + S, $25 \%$ of the normal fat was exchanged for Salatrim.

${ }^{*}$ Extracted from serum and tissue from fasted animals.

†The lean and obese groups serve as reference groups for comparison and are not included in the statistical analyses.

$\ddagger$ Results from the two-way ANOVA with $P<0.05$ and the treatment, FO or Salatrim that caused the effect. 

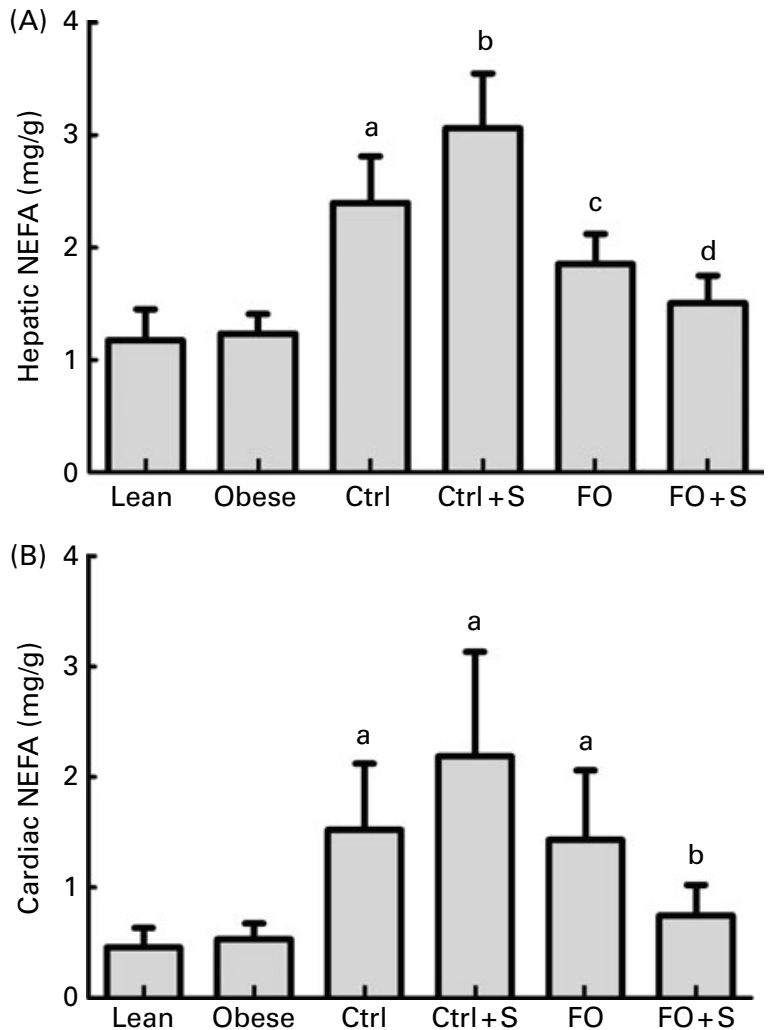

Fig. 3. The (A) hepatic and (B) cardiac concentrations of NEFA (in the four weight loss groups and the two reference groups. As the two-way ANOVA showed significant interaction, pair-wise $t$ tests were performed. ${ }^{a, b}$ Mean values with unlike letters are significantly different between groups. The two reference groups were not included in the tests. Ctrl, control diet; FO, fish oil diet; FO + S, $25 \%$ of the normal fat was exchanged for Salatrim.

\section{Discussion}

In the present study we have investigated how specific groups of dietary fatty acids and their interactions affect the rate of weight loss, metabolic function and risk factors related to the development of the metabolic syndrome in mice.

In our study, the inclusion of FO to a weight loss diet did not affect the rate of weight loss or fasting insulin. This is contrary to studies that have shown that the inclusion of $n-3$ LC-PUFA to a weight loss diet leads to increased rate of weight loss in humans ${ }^{(1-3)}$ and reduced fasting insulin in rodents ${ }^{(25)}$. However, anti-obesity effects are not a consistent finding in humans as other studies report no effect of $n$ - 3 LC-PUFA on the rate of weight loss ${ }^{(26,27)}$, whereas in rodents, the anti-obesity as well as insulin-reducing effects of $n-3$ LC-PUFA have been highly consistent during weight gain ${ }^{(28-33)}$. However, as our primary focus was to study the effects of a FO intake realistic for a human population, we have used substantially lower concentrations than earlier studies. Nakatani et al. ${ }^{\text {(28) }}$ compared the effect on weight gain of different amounts of FO fed to female $\mathrm{C} 57 \mathrm{BL} / 6 \mathrm{~J}$ mice, and found that less than 40 energy $\%$ FO was insufficient in reducing weight gain significantly compared with the no FO control. We gave the mice $4.5-6$ energy $\%$ FO, which corresponds to $12-15 \mathrm{~g} / \mathrm{d}$ of FO for a person consuming $10000 \mathrm{~kJ} / \mathrm{d}$, and higher intake might be unrealistic in a human nutritional context.
Furthermore, in contrast to earlier studies when FO was given during weight gain, we can also expect dilution of the fatty acids of dietary origin with fatty acids released from the adipose tissue during weight loss in the present study. Therefore, it is noteworthy, that the low doses used have been sufficient to improve hepatic and cardiac lipid status, proving that FO intake at these relatively low levels also improves metabolic status during weight loss.

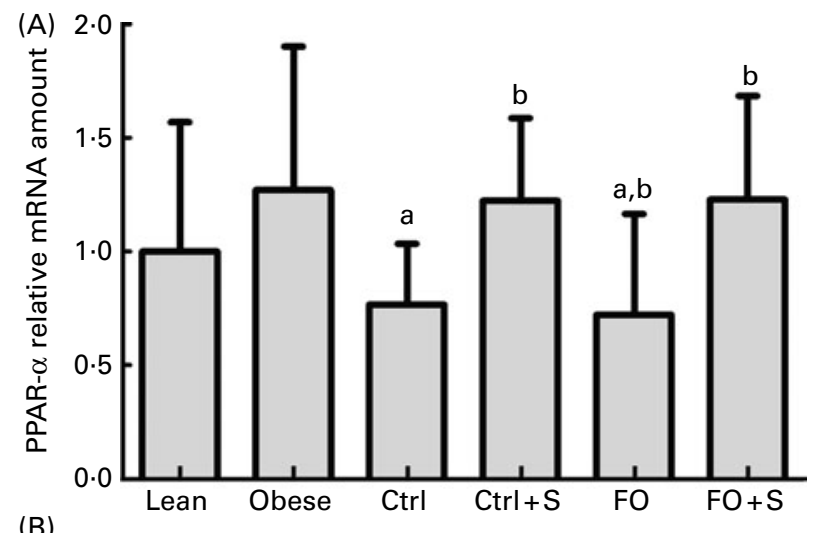

(B)

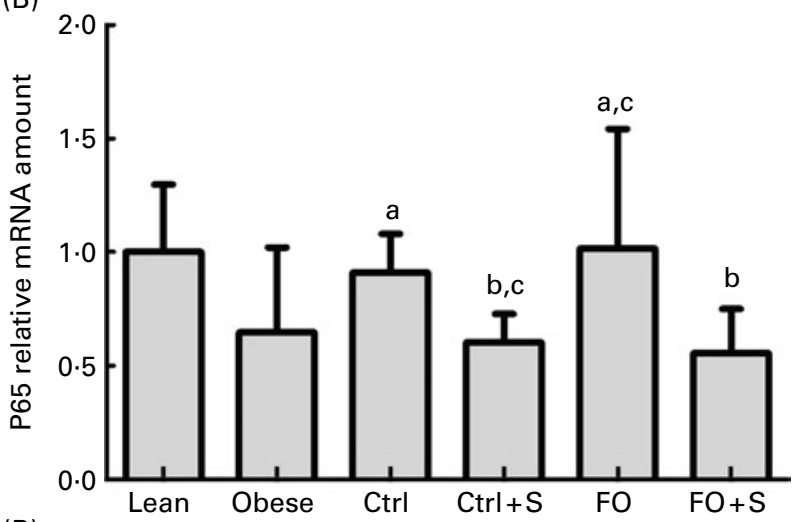

(B)

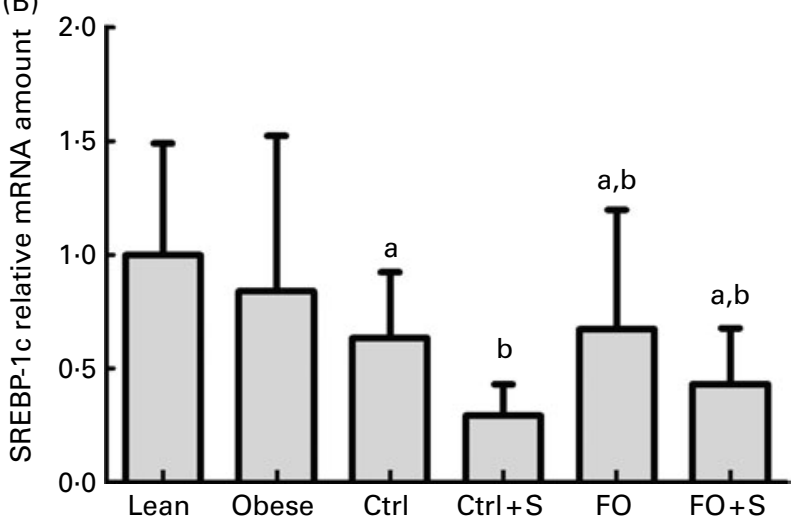

Fig. 4. The relative hepatic mRNA amount of (A) PPAR- $\alpha$, (B) NF-kB subunit P65 and (C) sterol regulatory element binding protein-1c (SREBP-1C) in the four different weight loss groups and the reference groups. The real-time quantitative PCR data are presented as mean and standard deviations relative to the mRNA level in the lean reference group, $n 8$. The two-way ANOVA includes only the four weight loss groups. For the relative hepatic mRNA amounts of PPAR- $\alpha$, P65 and SREBP-1c, two-way ANOVA showed an effect of Salatrim of $P<0.004, P<0.002$ and $P<0.003$, respectively. ${ }^{a, b, c}$ Mean values with unlike letters are significantly different between individual groups. Ctrl, control diet; FO, fish oil diet; FO + S, $25 \%$ of the normal fat was exchanged for Salatrim. 
Dietary $n$-3 LC-PUFA have been shown to prevent the development of insulin resistance in rodents when obesity is induced by a high-energy diet ${ }^{(29,33-35)}$, but the effect of administering $n$-3 LC-PUFA to obese animals during weight loss has, to our knowledge, not previously been investigated. A study by Ramel et $a l .{ }^{(36)}$ indicated that physiological doses of FO $(3 \mathrm{~g} / \mathrm{d})$ during weight loss would improve insulin sensitivity in humans, and in the present study we wanted to investigate the potential mechanisms for this effect. We hypothesised that the proposed anti-inflammatory effects of $n$-3 LC-PUFA could lead to a reduction of the inflammatory state of the adipose tissue, and that the activation of hepatic PPAR- $\alpha$ by $n$ - 3 LC-PUFA could induce the transcription of fat-oxidising enzymes and thus reduce hepatic lipid accumulation. Both of these effects were expected to improve insulin sensitivity, but no difference was seen in fasting insulin after 4 weeks on a FO diet compared with the Ctrl group that did not consume FO. Total macrophagal infiltration in the adipose tissue was assessed by the amount of mRNA encoding CD68, a macrophage surface receptor, and this was also not reduced by FO treatment. Total macrophagal infiltration, however, does not give information on the activation state of the adipose tissue macrophages, but as anti-inflammatory effects of FO on the amount of mRNA encoding TNF- $\alpha$ or NF-кB P65 were not found, an effect on the distribution between inflammatory M1- and anti-inflammatory M2-tissue macrophages is unlikely.

Hepatic NEFA and TAG accumulation was reduced by FO relative to the $\mathrm{Ctrl}$ fat, and in both cardiac and hepatic tissue the combination of FO and SCFA was particularly efficient in reducing NEFA accumulation. This shows that inclusion of FO and SCFA in weight loss diets might be a feasible strategy to optimise the improvement in tissue lipid status during weight loss. The increased load of NEFA in tissues is strongly linked to the accumulation of lipotoxic fatty acid derivatives, such as acyl-CoA, ceramide and diacylglycerol, which have been suggested to be part of the aetiology of both insulin resistance and $\mathrm{CVD}^{(37,38)}$. Hence, the increased load of cardiac and hepatic NEFA in the weight-loss groups given Ctrl fat, constitute a metabolic risk that, at least in mice, can be reduced through intervention with appropriate dietary fat during a weight-loss programme. The lipid-lowering effect of FO is consistent with the expected effect of $n-3$ LC-PUFA on PPAR- $\alpha$ and SREBP-1c in the liver. However, we did not find a significant increase in the mRNA amount of PPAR$\alpha$-regulated hepatic fat-oxidising enzymes that could explain this finding. Mori et al. ${ }^{(32)}$ were able to find significant increases in the mRNA amount and enzymatic activity of hepatic fat-oxidising enzymes in $\mathrm{C} 57 \mathrm{BL} / 6 \mathrm{~J}$ mice following 2 weeks on a FO diet. Their setup, however, differed from the present study as they fed the mice a weight-increasing diet.

In conclusion, we show that a (relatively) low-dose FO intervention is able to increase the rate of improvement of liver lipid levels during a weight-loss programme without a concomitant improvement of glucose tolerance or adipose inflammation, compared with weight loss on the Ctrl-fat diet.

We also investigated the effect of exchanging $25 \mathrm{w} \%$ of normal fat with Salatrim. This exchange was tried in combination with both Ctrl fat and FO in order to investigate the possible synergistic effects of the SCFA from Salatrim and $n$-3 LC-PUFA from FO. The weight loss after 4 weeks on low-energy diets was evident for all mice, but it was significantly greater when $25 \%$ of the fat was exchanged for Salatrim. The change in fasting insulin was highly correlated to weight change and additional improvements in the Salatrim groups were probably due to the difference in weight.

However, Salatrim also affected parameters which could not be explained by the reduced energy intake and increased weight loss. The amount of PPAR- $\alpha$ mRNA was higher, and that of NF- $\mathrm{B}$ p 65 subunit was lower in both adipose and hepatic tissues. We were able to show in vivo the effect of SCFA on the amount of PPAR- $\alpha$ mRNA, which had previously been shown only in in vitro experiment ${ }^{(19)}$. A higher expression of PPAR- $\alpha$ could explain the combined effect of SCFA and n-3 LC-PUFA on hepatic and cardiac NEFA levels. The transcription of many lipogenic enzymes is controlled by the transcription factor SREBP-1c, and a reduction in its activity could also lead to reduced fatty acid accumulation. We found a significant reduction in the amount of mRNA encoding this transcription factor following Salatrim treatment, but again without significant reductions in the amount of mRNA-encoding lipogenic enzymes under its control.

The source of SCFA in the present study was Salatrim, but fermentation of fibre by the gut microflora provides a natural source of SCFA, which has been measured to be $375 \mathrm{mmol} / 1$ in the human portal vein ${ }^{(39)}$. The finding that acetate and propionate in Salatrim seem to act as systemic transcriptional regulators therefore has more wide-reaching implications as it suggests that some of the systemic effects induced by interventions with pre- or probiotica might be explained by enhanced production of SCFA. Cell studies have shown reduced cytokine production following LPS stimulation of SCFA-treated neutrophils, and SCFA have furthermore been shown to inhibit the activity of NF- $\mathrm{B}$ in vitro. The present results, showing lower hepatic and adipose transcription of NF-кB p65 in the SCFA-treated mice, indicate that SCFA could also inhibit NF-кB activity in vivo, and that those anti-inflammatory effects of SCFA could reach the systemic circulation, although evidence of reduced inflammation was not found in the present study. Yin et al. ${ }^{(40)}$ have shown that SCFA treatment reduced IкB (NFкB inhibitor degradation after NF-кB stimulation in vitro, and it is possible that SCFA inhibit NF- $\kappa$ B activity by more than one pathway. Systemic inflammation is associated with the metabolic syndrome, and it is possible that SCFA mediate some of the beneficial effects of fibre consumption by its anti-inflammatory properties. An effect of SCFA on gene transcription could be mediated by the receptors, GPR41 and GPR43, which are widely distributed, although most commonly associated with adipocytes and immune cells ${ }^{(21)}$. SCFA have previously been shown to signal through these receptors ${ }^{(41)}$.

In conclusion, the addition of FO to a low-fat diet during weight loss did not reduce adipose inflammation and fasting insulin. However, exchanging $25 \mathrm{w} \%$ of the fat with Salatrim increased weight loss, lowered fasting insulin and altered the amount of mRNA encoding three important transcription 
factors, PPAR- $\alpha$, NF- $\kappa$ B and SREBP-1c, which are central in inflammatory response and fatty acid metabolism. However, the most important finding of the present study is the pronounced synergistic effect of FO and Salatrim on tissue NEFA, since a reduction in available NEFA may affect the concentration of lipotoxic fatty acid metabolites that have been implicated in the development of insulin resistance and CVD.

\section{Acknowledgements}

We thank Jannie Felskov Agersten and Pernille Wehler Güllich for technical assistance and DANISCO for financial support and for kindly providing us with the Salatrim used in the present study. This work was financially supported by the Danish Council for Strategic Research through the Program Committee for Food and Health, and DANISCO did not have any influence on the interpretation of the data or the writing of this paper. M. H. P., L. L. and L. I. H. have no conflict of interests. M. H. P. conducted the experiments and wrote the paper. L. I. H. developed the overall research plan in collaboration with L. L. All authors share responsibility of the final content.

\section{References}

1. Thorsdottir I, Tomasson H, Gunnarsdottir I, et al. (2007) Randomized trial of weight-loss-diets for young adults varying in fish and fish oil content. Int J Obes 31, 1560-1566.

2. Hill AM, Buckley JD, Murphy KJ, et al. (2007) Combining fish-oil supplements with regular aerobic exercise improves body composition and cardiovascular disease risk factors. Am J Clin Nutr 85, 1267-1274.

3. Kunesova M, Braunerova R, Hlavaty $\mathrm{P}$, et al. (2006) The influence of $n-3$ polyunsaturated fatty acids and very low calorie diet during a short-term weight reducing regimen on weight loss and serum fatty acid composition in severely obese women. Physiol Res 55, 63-72.

4. Sjoholm A \& Nystrom T (2006) Inflammation and the etiology of type 2 diabetes. Diabetes Metab Res Rev 22, 4-10.

5. Kanda H, Tateya S, Tamori Y, et al. (2006) MCP-1 contributes to macrophage infiltration into adipose tissue, insulin resistance, and hepatic steatosis in obesity. J Clin Invest 116, 1494-1505.

6. Lee YH, Nair S, Rousseau E, et al. (2005) Microarray profiling of isolated abdominal subcutaneous adipocytes from obese vs non-obese Pima Indians: increased expression of inflammation-related genes. Diabetologia 48, 1776-1783.

7. Curat CA, Miranville A, Sengenes C, et al. (2004) From blood monocytes to adipose tissue-resident macrophages - induction of diapedesis by human mature adipocytes. Diabetes $\mathbf{5 3}$, $1285-1292$.

8. Fain JN (2006) Release of interleukins and other inflammatory cytokines by human adipose tissue is enhanced in obesity and primarily due to the nonfat cells. Interleukins 74, 443-477.

9. Nieto-Vazquez I, Fernandez-Veledo S, Kraemer DK, et al. (2008) Insulin resistance associated to obesity: the link TNF-alpha. Arch Physiol Biochem 114, 183-194.

10. de Alvaro C, Teruel T, Hernandez R, et al. (2004) Tumor necrosis factor alpha produces insulin resistance in skeletal muscle by activation of inhibitor kappa B kinase in a p38 MAPK-dependent manner. J Biol Chem 279, 17070-17078.
11. Feinstein R, Kanety H, Papa MZ, et al. (1993) Tumornecrosis-factor-alpha suppresses insulin-induced tyrosine phosphorylation of insulin-receptor and its substrates. J Biol Chem 268, 26055-26058.

12. Boden G (2002) Interaction between free fatty acids and glucose metabolism. Curr Opin Clin Nutr Metab Care 5, 545-549.

13. Todoric J, Loffler M, Huber J, et al. (2006) Adipose tissue inflammation induced by high-fat diet in obese diabetic mice is prevented by $n-3$ polyunsaturated fatty acids. Diabetologia 49, 2109-2119.

14. Krebs JD, Browning LM, Mclean NK, et al. (2006) Additive benefits of long-chain $n-3$ polyunsaturated fatty acids and weight-loss in the management of cardiovascular disease risk in overweight hyperinsulinaemic women. Int $J$ Obes 30, 1535-1544.

15. Jiang CY, Ting AT \& Seed B (1998) PPAR-gamma agonists inhibit production of monocyte inflammatory cytokines. Nature 391, 82-86.

16. Guri AJ, Hontecillas R \& Bassaganya-Riera J (2006) Peroxisome proliferator-activated receptors: bridging metabolic syndrome with molecular nutrition. Clin Nutr 25, 871-885.

17. Jump DB, Botolin D, Wang Y, et al. (2005) Fatty acid regulation of hepatic gene transcription. J Nutr 135, 2503-2506.

18. Finley JW, Klemann LP, Leveille GA, et al. (1994) Caloric availability of salatrim in rats and humans. J Agric Food Chem 42, 495-499.

19. Zapolska-Downar D, Siennicka A, Kaczmarczyk M, et al. (2004) Butyrate inhibits cytokine-induced VCAM-1 and ICAM-1 expression in cultured endothelial cells: the role of NF-kappa B and PPAR alpha. J Nutr Biochem 15, $220-228$.

20. Maslowski KM, Vieira AT, Ng A, et al. (2009) Regulation of inflammatory responses by gut microbiota and chemoattractant receptor GPR43. Nature 461, 1282-1286.

21. Covington DK, Briscoe CA, Brown AJ, et al. (2006) The G-protein-coupled receptor 40 family (GPR40-GPR43) and its role in nutrient sensing. Biochem Soc Trans 34, $770-773$.

22. Tiwari A (2010) GPR43: an emerging target for the potential treatment of type 2 diabetes, obesity and insulin resistance. Curr Opin Investig Drugs 11, 385-393.

23. Folch J, Lees M \& Sloane Stanley GH (1957) A simple method for the isolation and purification of total lipides from animal tissues. J Biol Chem 226, 497-509.

24. Artmann A, Petersen G, Hellgren LI, et al. (2008) Influence of dietary fatty acids on endocannabinoid and N-acylethanolamine levels in rat brain, liver and small intestine. Biochim Biophys Acta 1781, 200-212.

25. Artmann A, Petersen G, Hellgren LI, et al. (2008) Influence of dietary fatty acids on endocannabinoid and N-acylethanolamine levels in rat brain, liver and small intestine. Biochim Biophys Acta 1781, 200-212.

26. Mori TA, Bao DQ, Burke V, et al. (1999) Dietary fish as a major component of a weight-loss diet: effect on serum lipids, glucose, and insulin metabolism in overweight hypertensive subjects. Am J Clin Nutr 70, 817-825.

27. Abete I, Parra D, Crujeiras AB, et al. (2008) Specific insulin sensitivity and leptin responses to a nutritional treatment of obesity via a combination of energy restriction and fatty fish intake. J Hum Nutr Diet 21, 591-600.

28. Nakatani T, Kim HJ, Kaburagi Y, et al. (2003) A low fish oil inhibits SREBP-1 proteolytic cascade, while a high-fish-oil feeding decreases SREBP-1 mRNA in mice liver: relationship to anti-obesity. J Lipid Res 44, 369-379. 
29. Ikemoto S, Takahashi M, Tsunoda N, et al. (1996) High-fat diet-induced hyperglycemia and obesity in mice: differential effects of dietary oils. Metabolism 45, 1539-1546.

30. Hassanali Z, Ametaj BN, Field CJ, et al. (2010) Dietary supplementation of $n$-3 PUFA reduces weight gain and improves postprandial lipaemia and the associated inflammatory response in the obese JCR:LA-cp rat. Diabetes Obes Metab 12, 139-147.

31. Arai T, Kim HJ, Chiba H, et al. (2009) Anti-obesity effect of fish oil and fish oil-fenofibrate combination in female KK mice. $J$ Atheroscler Thromb 16, 674-683.

32. Mori T, Kondo H, Hase T, et al. (2007) Dietary fish oil upregulates intestinal lipid metabolism and reduces body weight gain in C57BL/6J mice. J Nutr 137, 2629-2634.

33. Storlien LH, Kraegen EW, Chisholm DJ, et al. (1987) Fish oil prevents insulin resistance induced by high-fat feeding in rats. Science 237, 885-888.

34. Neschen S, Morino K, Dong JY, et al. (2007) N-3 fatty acids preserve insulin sensitivity in vivo in a peroxisome proliferator-activated receptor-alpha-dependent manner. Diabetes 56, 1034-1041.

35. Jucker BM, Cline GW, Barucci N, et al. (1999) Differential effects of safflower oil versus fish oil feeding on insulin-stimulated glycogen synthesis, glycolysis, and pyruvate dehydrogenase flux in skeletal muscle - a C-13 nuclear magnetic resonance study. Diabetes $\mathbf{4 8}, 134-140$.

36. Ramel A, Martinez A, Kiely M, et al. (2008) Beneficial effects of long-chain $n$-3 fatty acids included in an energy-restricted diet on insulin resistance in overweight and obese European young adults. Diabetologia 51, 1261-1268.

37. Trauner M, Arrese M \& Wagner M (2010) Fatty liver and lipotoxicity. Biochim Biophys Acta 1801, 299-310.

38. Szczepaniak LS, Victor RG, Orci L, et al. (2007) Forgotten but not gone: the rediscovery of fatty heart, the most common unrecognized disease in America. Circ Res 101, 759-767.

39. Cummings JH, Pomare EW, Branch WJ, et al. (1987) Short chain fatty-acids in human large-intestine, portal, hepatic and venous-blood. Gut 28, 1221-1227.

40. Yin L, Laevsky G \& Giardina C (2001) Butyrate suppression of colonocyte NF-kappa B activation and cellular proteasome activity. J Biol Chem 276, 44641-44646.

41. Ge HF, Li XF, Weiszmann J, et al. (2008) Activation of G protein-coupled receptor 43 in adipocytes leads to inhibition of lipolysis and suppression of plasma free fatty acids. Endocrinology 149, 4519-4526. 